\begin{tabular}{llll} 
Abstract P32 Table 1 & & \\
\hline & Monotherapy $(\mathrm{n}=15)$ & Combination $(\mathrm{n}=\mathbf{8})$ & Rescue $(\mathrm{n}=\mathbf{1})$ \\
\hline Haemostasis & $15 / 15(100 \%)$ & $7 / 8(88 \%)$ & $0 / 1$ \\
Re-bleeding & $3 / 13(23 \%)$ & $1 / 6(17 \%)$ & $\mathrm{n} / \mathrm{a}$ \\
7-day mortality & $1 / 13(8 \%)$ & 0 & 0 \\
30-day mortality & $2 / 13(15 \%)$ & 0 & 0 \\
\hline
\end{tabular}

There were no adverse events associated with Hemospray.

Outcomes in the Hemospray treatment subgroups (table 1). Conclusions Hemospray is safe and effective in LGIB's with 92\% haemostasis rates, with better outcomes as a Monotherapy. Anticoagulants have an effect on haemostasis rates $(78 \%$ vs $100 \%)$.

Lower GI bleeds are difficult to treat. Hemospray is an effective alternative in situations where access is difficult and there is a large surface of bleeding.

\section{P33 HEMOSPRAY TREATMENT IN NON-VARICEAL UPPER GASTROINTESTINAL BLEEDS: OUTCOMES FROM THE FIRST 500 HEMOSPRAY REGISTRY PATIENTS}

\footnotetext{
1,2 Mohamed Hussein*, 'Durayd Alzoubaidi, ${ }^{3}$ Michael Weaver, ${ }^{2}$ Christwishes Makahamadze, ${ }^{4}$ Alvaro de la Serna, ${ }^{5}$ Jacobo Ortiz Fernandez Sordo, ${ }^{6}$ Johannes W Rey, ${ }^{7}$ Bu Hayee, ${ }^{8}$ Edward Despott, ${ }^{8}$ Alberto Murino, ${ }^{9}$ Sulleman Moreea, ${ }^{10}$ Phil Boger, ${ }^{11}$ Jason Dunn, ${ }^{12}$ Inder Mainie, ${ }^{2}$ David Graham, ${ }^{3}$ Dan Mullady, ${ }^{3}$ Dayna Early, ${ }^{5}$ Krish Ragunath, ${ }^{13}$ John Anderson, ${ }^{14}$ Pradeep Bhandari, ${ }^{15}$ Martin Goetz, ${ }^{4}$ Enrique Rodriguez, ${ }^{16}$ Tamas Gonda, ${ }^{5}$ Ralf Kiesslich, ${ }^{17}$ Emmanuel Coron, ${ }^{1,2}$ Laurence B Lovat, ${ }^{1,2}$ Rehan Haidry. ${ }^{1}$ University College London, UK; ${ }^{2}$ University College London Hospital, UK; ${ }^{3}$ Washington University School of Medicine, USA; ${ }^{4}$ Hospital Universitario Ramón y Cajal, Spain; ${ }^{5}$ Nottingham University Hospitals, UK; ${ }^{6}$ Horst Scmidt Kliniken, Germany; ${ }^{7}$ Kings College Hospital, UK; ${ }^{8}$ Royal Free Hospital, UK; ${ }^{9}$ Bradford Hospital, UK; ${ }^{10}$ University Hospital Southampton, UK; ${ }^{11}$ Guys and St Thomas Hospital, UK; ${ }^{12}$ Belfast Health and Social Care Trust, UK; ${ }^{13}$ Gloucestershire Hospitals, UK; ${ }^{14}$ University of Portsmouth, UK; ${ }^{15} \mathrm{Klinikum}$ Sindelfingen-Böblingen, Germany; ${ }^{16}$ Columbia University, USA; ${ }^{17}$ University Hospital of Nantes, France
}

\subsection{6/gutjnl-2020-bsgcampus. 108}

Introduction Upper gastrointestinal bleeding (UGIB) is a leading cause of morbidity. The aim was to look at outcomes in patients with non-variceal UGIBs of all causes treated with Hemospray.

Methods Data was collected prospectively (Jan' 16- Nov'19) from 16 centres in the USA, UK, Germany, France and Spain. Hemospray was used during endoscopy as a monotherapy, dual therapy or rescue therapy. Haemostasis was defined as cessation of bleeding within 5 minutes of Hemospray application.

Results 512 patients with non-variceal UGIBs were recruited (343 male, 169 female). The most common cause was peptic ulcers $(236 / 512,46 \%)$.

Immediate haemostasis was achieved in $473 / 512$ (92\%) patients. Median Blatchford was 11 (IQR, 8-14), median Rockall was 7 (IQR, 6-8). Re-bleeding occurred in 59/404 (15\%) patients. There was a 7-day mortality (all cause) of $9 \%$ (42/444), 30-day mortality (all cause) was 19\% (85/444). The highest haemostasis rates were in the Hemospray monotherapy group (95\%).

39 patients did not achieve haemostasis (69\% were peptic ulcer related). 14/39 (36\%) of these patients had CT embolization, $7 / 39(18 \%)$ managed conservatively and 3/39 (8\%) had surgery.

\begin{tabular}{llllll} 
Abstract P33 & Table1 & & & \\
\hline & $\begin{array}{l}\text { Peptic } \\
\text { ulcers } \\
(\mathbf{n}=236)\end{array}$ & $\begin{array}{l}\text { Malignancy } \\
(\mathbf{n}=96)\end{array}$ & $\begin{array}{l}\text { Post } \\
\text { procedure } \\
(\mathbf{n}=73)\end{array}$ & $\begin{array}{l}\text { Inflammation } \\
(\mathbf{n}=20)\end{array}$ & $\begin{array}{l}\text { Angiodysplasia } \\
(\mathbf{n}=12)\end{array}$ \\
\hline $\begin{array}{l}\text { Median } \\
\text { Blatchford }\end{array}$ & $13(10-$ & $10(7-12)$ & $5(0-9)$ & $9(7-14)$ & $11(9-11)$ \\
(IQR) & & & & & \\
$\begin{array}{l}\text { Median Rockall } \\
\text { (IQR) }\end{array}$ & $7(6-8)$ & $8(7-9)$ & $6(5-7)$ & $7(6-8)$ & $6(5-7)$ \\
Haemostasis & $209 / 236$ & $93 / 96$ & $73 / 73$ & $19 / 20$ & $12 / 12$ \\
& $(89 \%)$ & $(97 \%)$ & $(100 \%)$ & $(95 \%)$ & $(100 \%)$ \\
Re-bleed & $34 / 181$ & $11 / 78$ & $2 / 57$ & $2 / 17$ & $2 / 11$ \\
& $(19 \%)$ & $(14 \%)$ & $(4 \%)$ & $(12 \%)$ & $(18 \%)$ \\
7-day mortality & $24 / 208$ & $2 / 81$ & $1 / 59$ & $4 / 18$ & 0 \\
& $(12 \%)$ & $(2 \%)$ & $(2 \%)$ & $(22 \%)$ & \\
30-day & $48 / 208$ & $16 / 81$ & $1 / 59$ & $6 / 18$ & 0 \\
mortality & $(23 \%)$ & $(20 \%)$ & $(2 \%)$ & $(33 \%)$ & \\
\hline
\end{tabular}

Outcomes in different UGI pathologies (table 1).

Conclusion There were high immediate haemostasis rates following treatment of non-variceal UGIBs. The better outcomes were when Hemospray was used in UGIB's post endotherapy, malignancy and Angiodysplasia. In malignancies it can bridge towards surgery/chemoradiotherapy, and post endotherapy it can provide definitive haemostasis with low re-bleed rates.

\section{P34 EFFECT OF BOWEL PREPARATION ON RENAL FUNCTION IN PATIENTS WITH AND WITHOUT CHRONIC KIDNEY DISEASE}

Ben Johnson*, Vanja Giljaca. University Hospitals Birmingham, Birmingham, UK

\subsection{6/gutjnl-2020-bsgcampus.109}

Aims Records for patients who underwent colonoscopy and who received a $2 \mathrm{~L}$ polyethylene glycol (PEG) bowel preparation were reviewed to evaluate whether there is any effect on renal function in those patients with chronic kidney disease (CKD) versus those without.

Methods We screened 1000 randomly chosen patients from a pool of 2128 colonoscopies in 2017. Data were collected on quality of bowel preparation, history of $\mathrm{CKD}$, and creatinine and an estimated glomerular filtration rate (eGFR) in the 60 days before and after colonoscopy. Patients with CKD were defined as those patients with a documented diagnosis or an eGFR of less than 60 for more than 3 months.

Results Bowel preparation quality was good or excellent in $41 \%$ of patients. Out of 1,000 patients, only $20.9 \%$ (n = 209) had their renal function checked both 60 days before

\section{Abstract P34 Table 1}

\begin{tabular}{llll}
\hline & $\begin{array}{l}\text { No. of } \\
\text { Patients }\end{array}$ & $\begin{array}{l}\text { \% Creatinine } \\
\text { Change }\end{array}$ & $\begin{array}{l}\text { \% eGFR } \\
\text { Change }\end{array}$ \\
\hline Patients with CKD & 58 & $4.70 \%$ & $2.60 \%$ \\
Patients without CKD & 151 & $1.30 \%$ & $0.05 \%$ \\
Significance of\% Change in CKD vs & & $\mathrm{p}=0.18$ & $\mathrm{p}=0.18$ \\
Non-CKD & & & \\
\hline
\end{tabular}


and after colonoscopy. Of these, 28\% $(\mathrm{n}=58)$ had a history of CKD. Overall, there was no statistically significant difference in the change in eGFR before and after colonoscopy for patients without CKD compared to those with CKD ( $\mathrm{p}=$ 0.18 ). There were only five patients with eGFR of $<30 \mathrm{~mL} /$ $\min$ and in this subgroup there was no significant renal impairment after colonoscopy. There were no acute kidney injuries in both groups.

Conclusions The data show that 2L PEG solution is safe in patients with impaired renal function. Routine screening for $\mathrm{CKD}$ in patients undergoing bowel preparation for colonoscopy may not be justified.

\section{P35 OPINIONS OF UK GASTROENTEROLOGY CONSULTANTS IN THE APPLICATION OF ARTIFICIAL INTELLIGENCE IN ENDOSCOPY}

1,2 Rawen Kader* ${ }^{2}$ Mohamed Hussein, 1,20mer F Ahmad, 1,2 Danail Stoyanov, 1,2,3 B Lovat. "Wellcome/EPSRC Centre for Interventional and Surgical Sciences (WEISS), UCL, London, UK; ${ }^{2}$ Division of Surgery and Interventional Sciences, UCL, London, UK; ${ }^{3}$ University College London Hospital (UCLH), London, UK

10.1136/gutjnl-2020-bsgcampus. 110

Introduction Recent advances in artificial intelligence (AI) have resulted in new AI applications for endoscopy. The aim of this study is to provide insight into the opinions of key leaders in Gastroenterology in the UK of these technologies.

Methods An anonymous quantitative questionnaire was administered to 22 UK Gastroenterology consultants at a dedicated $\mathrm{AI}$ in Gastroenterology national consensus conference. Baseline demographic data and previous colonoscopy experience for each participant was collected. The questionnaire explored the following topics:

- How AI in endoscopy might impact on an endoscopist's pattern recognition of lesions if they are a novice or an expert

- Likelihood that endoscopists might lose the competence to override AI diagnosis

- Support for using AI in endoscopy if it improves clinical patient outcomes but remains a black box

- Apportion of liability for misdiagnosis if a lesion is 'missed' during colonoscopy assisted by an AI polyp detection system

- The perceived risk of a two-tier healthcare system emerging in the NHS between those hospitals which do and do not use AI support

Results The questionnaire was completed by 22 participants. Two incomplete forms were excluded. Participants' demographic data and colonoscopy experience are shown in table 1.

Abstract P35 Table 1 Participants' demographic data and
colonoscopy experience
\begin{tabular}{|l|l|}
\hline Total number of participants & 20 \\
\hline Male & $90 \%(18 / 20)$ \\
\hline Female & $10 \%(2 / 20)$ \\
\hline Average Age & 44 years old \\
\hline JAG accredited & $20 / 20(100 \%)$ \\
\hline BCSP accredited & $9 / 20(45 \%)$ \\
\hline $\begin{array}{l}\text { Average number of colonoscopies } \\
\text { performed }\end{array}$ & $8094($ range $=1,000-30,000)$ \\
\hline $\begin{array}{l}\text { Previous experience in using AI device in } \\
\text { endoscopy }\end{array}$ & $12 / 20(60 \%)$ \\
\hline
\end{tabular}

Most participants think AI would improve endoscopist visual pattern recognition skills, more for novices (75\%) than for experts (55\%). The majority (65\%) recognised the risk that in future, endoscopists may lose the competence to override AI diagnoses, but only a minority of $15 \%$ thought this was likely.

There was a strong consensus (60\% for, 20\% against) that an unexplainable but clinically efficacious AI system would be acceptable, but there were concerns of a two-tier healthcare system emerging with a quarter thinking this was likely and the majority of $60 \%$ recognising that this was possible. A clear majority of $70 \%$ thought that the endoscopist should be liable for any misdiagnosis, with 10\% considering that liability should lie with the hospital and 5\% with the AI manufacturer; $15 \%$ were uncertain about how to apportion liability. Discussion Consultants in this study support the use of clinically efficacious AI systems in endoscopy regardless of 'explainability' but careful consideration is required to prevent a two-tier healthcare system emerging and to determine liability in the event of misdiagnosis.

Consideration is needed on how to monitor endoscopist skills given concerns that use of AI could result in endoscopist losing the competence to override AI diagnoses.

\section{P36 VALIDATING THE POST-COLONOSCOPY COLORECTAL CANCER (PCCRC) RATE AS A METRIC OF ENDOSCOPY QUALITY}

Javaid Subhani, Mohiuddin Khan*, Madeleine Frank. Basildon and Thurrock University Hospital, Basildon, UK

\subsection{6/gutjnl-2020-bsgcampus.111}

Introduction Endoscopists PCCRC rates have been shown to inversely correlate with their adenoma detection rates. The World Endoscopy Organisation (WEO) has recently published methodology for comparing unadjusted PCCRC rates between different organisations. These whole system rates may not reflect endoscopists' performance. This study aimed to produce a validated PCCRC rate for individual endoscopists.

Methods All cases of Colorectal cancer (CRC) diagnosed between 2010 and 2018 at our Trust were ascertained from Somerset Cancer Database using ICD10 codes C18-20. From the Endoscopy reporting system all colonoscopies performed in the same years were identified. By SQL queries within a MS Access database the following were determined for the 6 years 2010- December 2015.

- unadjusted PCCRC cases i) True +ve CRC diagnoses by colonoscopy ii) Cases with 2 colonoscopies within 6/12 of diagnosis.

Cases reviews took place for group i) and iii). The following variations in the WEO method were used to produce an Endoscopy-related PCCRC rate.

Exclusions

a. Genetic syndromes, IBD and follow-up recurrent EMR cases.

b. Delays in management not due to failure of endoscopic assessment

c. Errors in recorded timings for date of CRC diagnosis.

d. Inaccurately coded cases

Results From 2010-2015, 21267 colonoscopies were performed. From 2010-2018 1916 CRC cases diagnosed, 1246 (65\%) were diagnosed by colonoscopy.

39 unadjusted PCCRC cases were identified. After case review 18 cases were excluded by the criteria above, a (5), b 